\title{
QUALITY EVALUATION OF INTERNET WEBSITES WHICH REPRESENTS THE LITHUANIAN BASKETBALL THROUGH CONSUMERS APPROACH
}

\author{
Antanas Ūsas, Edmundas Jasinskas, Dalia Štreimikienė, Biruta \\ Švagždienè, Artūras Simanavičius
}

\section{Introduction}

Information communication technologies (ICT) over the last five years have become one of the main parts of the society. Smartphones, personal computers have become an integral part of everyday life. E-commerce is a very relevant subject and the topic is discussed around the world. In 2013, $41 \%$ of all internet users had purchased online and sales in 2015, reach $\$ 1,471$ billion (statista.com, 2016).

To ensure the quality of the website certain actions are carried out: planning and design, implementation, overview and evaluation. The evaluation is needed in order to observe, how the website works for consumers, what kind of emotions user feels, and what kind of quality he understands using website.

The quality management was researched by Ciarniene, Vienazindiene, and Vojtovic (2017), Tamuliene and Murzaite (2013), Vasauskaite and Streimikiene (2014), Malakauskaite and Navickas, (2010), Vveinhardt, Andriukaitiene and Grancay (2015), Jasinskas, Reklaitiene and Svagzdiene (2013), Ciegis, Dilius, Mikalauskiene (2015), Alonso Dos Santos, Calabuig Moreno, Montoro Rios, Valantine and Emeljanovas (2014). Gonzalez et al. (2015) says that the information contained on the website is very short life time, so it is necessary to frequently update the site information. Best way to do that is communicate with website developers and website users. Evaluation is necessary before website show up in internet, at website life time, and when website starts to lose users. Website evaluation creates or helps maintain competitive advantage. High quality of website promotes valuable feedback from customers, increase number of users, and turn some customers to loyal customers. Problem is how consumers assess the quality of the Lithuanian basketball representative sports Web sites?

Research objective - Lithuanian basketball representing internet website quality.

The aim of the research is to evaluate the quality of internet websites which represents the Lithuanian basketball through consumer's approach.

Research tasks are as follows:

1. To distinguish the strengths and weaknesses of quality measuring models.

2. To identify the quality of internet websites that represents the Lithuanian basketball through consumers 'emotions.

The following methods were applied: scientific literature analysis (to reveal the most useful model, select best model to evaluate Lithuanian basketball represented websites); observation (to find out what kind of emotions consumer feel when he is browsing website, and see where consumers look first, where he focusses.); questionnaire (to find out consumer opinion about different parts of website, how he evaluates website overall.).

The object of the article is application of strategic planning activities.

\section{Website Evaluation Methods}

The overviews of evaluation models show up that usually there are three types of different models. According to Yoo and Donthu (2001), Santouridis et al. (2012), Gonzalez et al. (2015) first and most popular model for evaluating the quality of a Website is a "Quality" model. It has different dimensions that show up users or developers and users quality understanding. Second evaluation group is "Usability” models. According to Wang and Senecal (2007), Nathan, 
and Yeow (2009), Islam and Tsuji (2011) models orientate to speed and convenience. Third group of models is "Satisfaction". These models according to Muylle et al. (2004), Schaupp (2010) show how much users satisfied with the quality that they get. Models are orientated in long term surfing and loyalty. In order to determine which model is most suitable for a particular website it is necessary to review different models in all three categories (Quality, Usability and Satisfaction).
Evaluation model groups analysis. In order to choose the best model for the evaluation, it was decided to compare the models (Quality, Usability and Satisfaction), compare their advantages and disadvantages. Most of the model's dimensions are the contents, information, comfort and ease to use, the layout of the page, technical parameters, and feedback.

Quality evaluation models are most universal compared with usability and satisfaction.

\section{Tab. 1: Model group comparison}

\begin{tabular}{l|c|c|c}
\multicolumn{1}{c|}{ DimensionlModel group } & Quality & Usability & Satisfaction \\
\hline Information & + & + & + \\
\hline Design & + & + & + \\
\hline Technical & + & + & + \\
\hline Versatility & + & + & \\
\hline Emotion & + & & \\
\hline
\end{tabular}

Source: own according to Gonzalez et al. (2015), Wang and Senecal (2007),

Schaupp (2010), Santouridis et al. (2012)

Quality models include the applicability of the technology to the emotional state of the user. These models are used in different kind of websites. The main dimensions of models are: ease of use, benefit to the consumer, the attractiveness of the website and loyalty (Yoo \& Donthu, 2001; Gonzalez et al., 2015; Santouridis et al., 2012). Models can be use in both terms of users and administrators. Main disadvantage of models is small feedback.

Usability evaluation model is totally different; it is targeting technical parameters and visual layout. The accuracy of the model is very good. There is ability to calculate data in separate ways. When researchers' applicate this model, they often target to one specific element of the website they wish to examine (Wang \& Senecal, 2007). Main disadvantage of this model is high specificity of one area. Most commonly they forgot to include user opinion about overall quality. Users often are not so familiar with the website that would be able to deal with specific problems. This model must get some feedback from users before start using it.

Satisfaction evaluation model is targeting user behavior. This model is not as popular as
Quality or Usability models. Satisfaction model advantage is applicability. It could be adapted to a variety of websites and get enough accurate information (Schaupp, 2010). Model usually has availability of information, ease of use and performance, dimensions. Main disadvantage of model is to small particularity. Dimensions of models often do not cover all elements of the website.

By comparing these three model's groups (Quality, Usability, and Satisfaction) some uniqueness was observed. Quality model group stood out in its versatility, information quality, and adaptability. Usability models were more detailed in technical part and simulation. Satisfaction models stood out for easy applicability and strong user opinion. The Quality models group is best suited for nowadays webpage research. These versatile models are ideal for modern webpages, which are often very different and universal. These models include not only technical and consumer reviews settings, but also psychological. Psychological settings are very important in nowadays society because, competition between websites is very intense, and the 
result - if the user won't feel emotionally good he will leave that website.

„Quality“ models. Quality models are most often used to evaluate websites. Yoo and Donthu (2001) 'SITEQUAL' model is most commonly used in online stores. This model is used to investigate the online marketing places, check out how the quality affects visitors' behavior. For example - visit and purchase decisions. Model helps to improve quality of the website from former users' perceived quality. Model has 4 main dimensions:

1. Ease of use: the ease of use and ability to search for information;

2. Aesthetic design: the creativity of a site with excellent multimedia and color graphics;

3. Processing speed: the promptness of online processing and interactive responsiveness to a consumer's requests.

4. Security: the security of personal and financial information.

To evaluate internet store quality, it is necessary to add an extra factor (Yoo \& Donthu, 2001; Webb \& Webb, 2004):

1. Competitive value: the competitive pricing in comparison to conventional retail stores or competing Internet shopping sites;

2. Clarity of ordering: the clarity of the ordering process supported by unambiguous pricing and fast delivery;

3. Corporate and brand equity: the name value of the site owner and the products or services on the website;

4. Product uniqueness: the uniqueness of the products or services on the website, such that visitors have difficulty finding the products elsewhere;

5. Product quality assurance: the consumer's self-assurance of product quality obtained during the interaction with the site and not necessarily associated with direct product purchase or consumption experience.

The model shows us, that website quality is made from service quality and information quality. Service quality has 5 factors - reliability, responsiveness, assurance, empathy and tangibility. Information quality has 4 factors accessibility, contextual, representational and intrinsic. Questions numbers variate depends on details and research goals. This "SiteQual" model was used in eBay, Amazon and Walmart.

Santouridis et al. (2012) provides electronic service quality model - E-S-Qual. This model was created from SiteQual model.
The difference is that this model can be used in all types of website. Authors add more questions about users' opinion, and feedback. E-S-Qual has three main aspects, website quality, created value and user loyalty. Model also has four main dimensions:

1. Efficiency. The ease and speed of accessing and using the site. Efficiency is considered very important in e-commerce, since convenience and saving of time are generally considered as the main reasons for shopping online.

2. Fulfillment. The extent to which the site's promises about order delivery and item availability are fulfilled. Fulfillment is one of the most vital factors for the judgment of the quality of an online shop, since keeping service promises and accurate order fulfillment are elements of service quality that lead to customer satisfaction or dissatisfaction.

3. System availability. The correct technical functioning of the website. When consumers purchase from an online shop or they are just surfing, function problems like nonworking buttons or missing links, disappoint customers and can lead to exiting (Wachter, 2002).

4. Privacy. The degree to which the site is safe and protects customer information. Many people are still not willing to purchase products from the internet because of the risk that is related to fraud of personal information (Yoo \& Donthu, 2001).

This model explains why customer leave's the website. Model also investigates customer demographic questions, and tells your website target market group. Model has strong side of customer loyalty and value that customer gets from website. Questionnaire was made from 22 questions, which can change depending on website. Model shows that efficiency, system availability, fulfilment and privacy dimensions have tree main goals, overall quality, perceived value, and loyalty. Goals can be reached only when you know control variables (Santouridis et al., 2012). This model mostly use in catalogs and web stores.

Gonzalez et al. (2015) used traditional model "WebQual" to evaluate sport websites. "WebQual" model was created in 2007 by Watson and Goodhue. This model is universal, used in different type of websites. This model can be changed depending on needs and goals. 
This model shows the point where website can be improved. Gonzalez et al. (2015) create perceived website quality graphic model based by "WebQual".

This model has four main categories:

1. Usefulness. This category includes informational fit to task, tailored communications, and trust and response time. Each subcategory has 3 or 4 questions.

2. Easy to use. This category includes easy of understanding and intuitive operations, subcategories.

3. Entertainment. This category includes visual appeal, innovativeness and emotional appeal subcategories. This category makes model exceptional because it has emotional and visual appeals.

4. Complementary relationship. This category includes consistent image and online completeness.
Model perfect fits to evaluate all kind of websites. This model is most popular from quality measurements models. Disadvantage is that there is only couple question about loyalty and feedback. Model is used to evaluate FC Barcelona, Manchester United, Liverpool, Real Madrid websites.

Quality evaluation model analysis. A table was made, in order to find out which model is the best. These models were selected because they are most popular and universal. Dimensions ware taken from all models and put in Tab. 2.

Easy to use is one of most important elements of website, which represents website customer attention to details and comfortable layout (Santouridis, 2012). This dimension shows how much time user spends in website and how much effort needs to find what he/she wants. All models evaluating website quality are

\section{Tab. 2: Quality model group comparison}

\begin{tabular}{l|c|c|c}
\multicolumn{1}{c|}{ DimensionIModel } & SiteQual & E-S-Qual & SportQual \\
\hline Easy to use & + & + & + \\
\hline Information & + & + & + \\
\hline Entertainment & & + & + \\
\hline Security & + & & + \\
\hline Feedback & & & + \\
\hline Extra sources & & & + \\
\hline
\end{tabular}

Source: own referring Yoo and Donthu (2001), Gonzalez et al. (2015), Santouridis et al. (2012)

included in this dimension; each model has 3-4 questions related with this dimension.

Information is the most important website element. Everyone is looking for information all the time. Information presentation depends if customer wants to come back for one more time Rocha (2012), AbuAli and Addose (2011). All models have this dimension. This dimension includes questions about information quality, respawn time, personal information.

Security is very important for customers who visiting or buying first time in website. In this dimension, most questions is about technical options. All models have this dimension. Mostly question is about browsing speed, personal information, security feeling. All models are equal in this dimension.
Feedback is a process which shows customer loyalty for website. It can be show in couple ways, first customer can come back second time and so on, second can recommend website for this friends and other potential customers (Silva \& Wijayaratntne, 2015). Quality models didn't separate this dimension from others. Models include this dimension to "Easy to use" dimension.

Extra sources are an extra category which includes extra questions. Questions depend on research goals and website specific. Only "SportQual" model has this dimension. This dimension allows getting information about specific details which are not included in other dimensions (Gonzalez et al., 2015).

A review of quality models shows that best model is Gonzalez et al. (2015) „SportQual“. 
This model best represents modern website evaluation. Main advantage is that model has question related with customer emotions.

\section{Research Methodology}

After the analysis of the scientific literature, research object was selected internet website quality of Lithuania basketball sites.

Research methods:

1. Questionnaire. After visiting websites, respondent filled the questionnaire which was made from Gonzalez et al. (2015) „Web quality“ and Ciu and Won (2016) „Sport web quality" questionnaires.

2. Emotion and eye movement tracking. The respondents are filmed when they browse websites. They facial emotions and eye movement in website was video recorded.

These methods allow getting best possible reliability of data. Methods also allow collect more data then casual methods. Eye tracking device will help you to see whether the respondents really got in touch with the Web site. The emotion reading software will help you identify the emotions raised by the respondent website

Data and participant's collection. It was not possible to interview large population of people because of all equipment. Therefore "selection by target" was chosen. There were selected students who are studying sport management. Respondents voluntarily chose to participate in the study.

The progress of the investigation and analysis:

1. The respondent sits down at the computer which is prepared, he is explained about the purpose of the investigation and other questions.

2. Calibration with Tobbi Eye $X$, video recording program turned on.

3. Respondent browsing websites. They are free to select everything they want. There is no task for them just look around. There is no time limit.

4. After website browsing respondent fill up a questionnaire. Respondents evaluate performance, security, usability, technical parameters, visual attraction and attachment (feedback). Saved video recorded files.

5. Test data processing and analysis using MS Excel, SPSS 17, FaceReader 6, or MSScreen programs.

$\square \quad$ The total study time $-1: 39: 54 \mathrm{~h}$.

$\square$ Average browsing time - 3min 19 seconds.

$\square \quad$ There were total 30 participants.

\section{Fig. 1: Questionnaire evaluation results by dimensions}

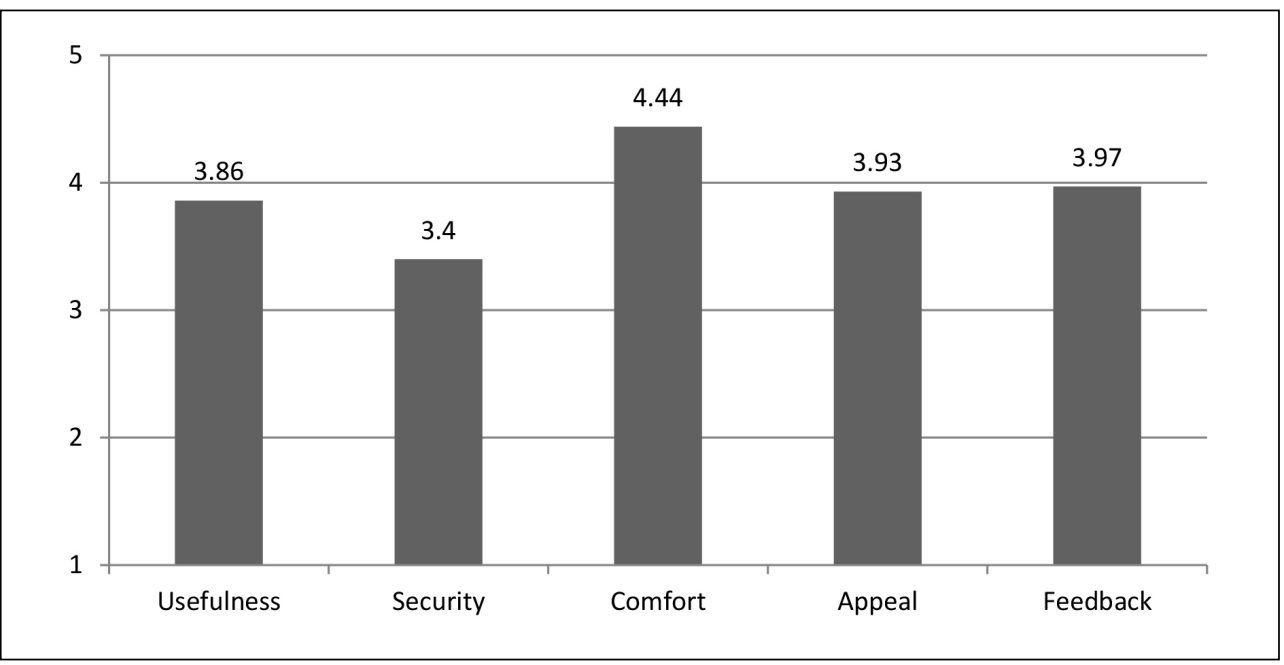




\section{Research Results}

The first questions about the quality of sites, has been focusing on performance, safety, comfort, attractiveness, and feedback. The questionnaire made by Likert-scale principle, respondents evaluated the different categories from 1 up to 5 points. The best respondents appreciated the comfort category, which highlighted the excellent page layout and ease of use (Fig. 1.).

Lowest scores gathered security category, respondents did not want to provide personal data to Websites. The reason for this is unnecessary advertising, huge information number and other unnecessary emails. The total score of the websites is 3.92, which respondents evaluated as good.

Following the emotions, results have been received from FaceReader 6 . Results were grouped together; dominated emotions and average of emotion were found. Total browsing time was around 1 hour and $40 \mathrm{~min}$. Average spend time in websites was 3 minutes and 19 seconds. Longest browsing time was 6 minutes 8 seconds, shortest 1 minute 12 seconds.

Throughout all research neutral and negative emotions were dominating. In the entire emotion schedule (Fig. 2) we can see total length of emotion expression.

\section{Fig. 2: All research emotions}

Neutral emotion represented $36.11 \%$ of all respondents. Neutral emotion dominates most of the time. Neutral emotion you can see from the beginning until the end of research. Other dominant emotion was anger $19.75 \%$. Participants look like more focus then angry. Next one was "other" emotions, this emotion was $15.8 \%$ of all time. These emotions express when there is no dominating emotion. This other emotion you can see in all 30 participant cases.
In every case, other emotion variate from $0.2 \%$ to $12.8 \%$ of time. Next emotion was disgusted $13.46 \%$ of time, this emotion was dominating in 8 cases. Happy emotion takes $5.66 \%$ of all time, most of the time this emotion express when person finish or start a research. Same with surprised emotion, which takes $5.14 \%$ of research time. Then was very rare emotions - scared and sad emotion which takes $2.12 \%$ and $1.95 \%$ of all time. 


\begin{tabular}{l|c|c|c|c|c|c} 
EmotionlEvaluation & Usefulness & Security & Comfort & Appeal & Feedback & Overall \\
\hline Positive & 3.81 & 3.42 & 4.35 & 3.89 & 3.84 & 3.86 \\
\hline Neutral & 3.50 & 3.17 & 4.92 & 3.92 & 3.70 & 3.84 \\
\hline Negative & 3.97 & 3.56 & 4.47 & 4.00 & 4.01 & 4.00 \\
\hline
\end{tabular}

\section{Tab. 4: Compare of last emotion and questionnaire evaluation}

\begin{tabular}{l|c|c|c|c|c|c} 
EmotionlEvaluation & Usefulness & Security & Comfort & Appeal & Feedback & Overall \\
\hline Positive & 4.27 & 3.82 & 4.75 & 4.03 & 4.11 & 4.20 \\
\hline Neutral & 4.20 & 3.59 & 4.48 & 4.21 & 3.82 & 4.02 \\
\hline Negative & 4.08 & 3.24 & 4.31 & 3.84 & 3.21 & 3.74 \\
\hline
\end{tabular}

Source: own

It was decided to compare the respondents experienced a positive and neutral and negative emotions throughout investigation results.

It can be seen in Tab. 3 that the negative emotions experienced persons throughout investigation, total evaluation was 0.14 better than that of respondents with neutral-positive emotions. Four of the five evaluation categories were better of negative emotions experienced respondents. The calculation of the data in the program SPSS 17 showed that there is no statistically significant difference between the data $p<0.05$. Then it was decided to make calculation of last second emotions and questionnaire results.

In the following table (Tab. 4), the emotions on which respondents ceased at the end of browsing is seen. Most respondents $n=12$ emotions were positive while throughout the investigation. With neutral emotions ended 10 respondents while browsing the websites, neutral emotion dominates in 16 times out of 30 . Only 8 respondents had negative emotion at the end of research. As we can see there is more positive than negative emotion at the end of research. Respondents, who have positive emotion, better evaluate usefulness, safety, convenience and feedback categories. After data calculation with SPSS 17, it was noticed that in the data there is statistically significant difference $p>0.05$. The emotions which were experienced during the research was statistically insignificant influence but emotions experienced the last browsing minutes have statistically significant influence.

\section{Conclusions}

Analyzing techniques of evaluation three different groups were separated - quality, usability and satisfaction. The first advantage is the versatility of the methodology of the evaluation of quality and detail, while the disadvantage is the excess of information. Second methodology advantage is accuracy and clarity, main disadvantage is feedback. The advantage of the third methodology is flexibility and speed, disadvantages is low detail. The best technique - quality, which is the most universal and informative defining with other techniques.

The quality of internet websites which represents the Lithuanian basketball satisfies the needs of consumers. The emotions which were experienced during the research were statistically insignificant influence but emotions experienced the last browsing minutes have statistically significant influence. Users, who had experienced positive emotions in the end of browsing, tend to evaluate the internet website better. It is important for organizations to manage their internet website that visitors leave it with positive emotions. 


\section{References}

Abu Ali, A. N., Abu-Addose, H. Y. (2011). A comparative study of techniques used for evaluating web page quality of the public organizations in Jordan Jordan-Amman. International journal of academic research, 3(2), 655-672.

\section{Alonso Dos Santos, M., Calabuig} Moreno, F., Montoro Rios, F., Valantine, I., \& Emeljanovas, A. (2014). Destination image of a city hosting sport event: Effect on sponsorship. Transformations in Business \& Economics, 13(2 A), 343-359.

Al-Qeisi, K., Dennis, C., Alamanos, E., \& Jayawardhena, C. (2014). Website design quality and usage behavior: Unified Theory of Acceptance and Use of Technology. Journal of Business Research, 67(11), 2282-2290. https://dx.doi.org/10.1016/j.jbusres.2014.06.016.

Chiu, W., \& Won, D. (2016). Relationship Between Sport Website Quality and Consumption Intentions Application of a Bifactor Model. Psychological Reports, 118(1), 90-106. https://dx.doi.org/10.1177/0033294115625269.

Ciarniene, R., Vienazindiene, M., \& Vojtovic, S. (2017). Process Improvement for Value Creation: a Case of Health Care Organization. Engineering Economics, 28(1), 79-87. https://dx.doi.org/http://dx.doi.org/10.5755/j01. ee.28.1.16601.

Ciegis, R., Dilius, A., \& Mikalauskiene, A. (2015). Evaluation of economic growth in terms of sustainability. Transformation in Business \& Economics, 14(1), 105-125.

Elling, S., Lentz, L., de Jong, M., \& Van den Bergh, H. (2012). Measuring the quality of governmental websites in a controlled versus an online setting with the 'Website Evaluation Questionnaire'. Government information quarterly, 29(3), 383-393. https://dx.doi. org/10.1016/j.giq.2011.11.004.

Gonzalez, M. E., Quesada, G., Davis, J., \& Mora-Monge, C. (2015). Application of Quality Management Tools in the Evaluation of Websites: The Case of Sports Organizations. Quality Management Journal, 22(1), 30-46. https://dx.doi.org/10.1080/10686967.2015.11918417.

Huang, W., Le, T., Li, X., \& Gandha, S. (2006). Categorizing web features and functions to evaluate commercial web sites: An assessment framework and an empirical investigation of Australian companies. Industrial Management \& Data Systems, 106(4), 523-539. https:// dx.doi.org/10.1108/02635570610661606.
Islam, A., \& Tsuji, K. (2011). Evaluation of usage of university websites in Bangladesh. DESIDOC Journal of Library \& Information Technology, 31(6), 469-479.

Yoo, B., \& Donthu, N. (2001). Developing a scale to measure the perceived quality of an Internet shopping site (SITEQUAL). Quarterly journal of electronic commerce, 2(1), 31-45.

Jasinskas, E., Reklaitiene, D., \& Svagzdiene, B. (2013). Evaluation of service quality in fitness centers. Transformations in Business \& Economics, 12(1), 108-124.

Law, R., Leung, R., \& Buhalis, D. (2009). Information technology applications in hospitality and tourism: a review of publications from 2005 to 2007. Journal of Travel \& Tourism Marketing, 26(5-6), 599-623. https://dx.doi. org/10.1080/10548400903163160.

Loiacono, E. T., Watson, R. T., \& Goodhue, D. L. (2007). WebQual: An Instrument for Consumer Evaluation of Web Sites. International Journal of Electronic Commerce, 11(3), 51-87. https://dx.doi.org/10.1108/14635770910948259.

Malakauskaite, A., \& Navickas, V. (2010). Relation between the level of clusterization and tourism sector competitiveness. Engineering economics, 66(1), 60-67.

Muylle, S., Moenaert, R., \& Despontin, M. (2004). The conceptualization and empirical validation of web site user satisfaction. Information \& management, 41(5), 543-560. https://dx.doi. org/10.1016/S0378-7206(03)00089-2.

Nathan, R. J., \& Yeow, P. H. (2009). An empirical study of factors affecting the perceived usability of websites for student Internet users. Universal Access in the Information Society, 8(3), 165-184. https://dx.doi.org/10.1007/ s10209-008-0138-8.

Rocha, Á. (2012). Framework for a global quality evaluation of a website. Online Information Review, 36(3), 374-382. https://dx.doi.org/10.1108/14684521211241404.

Santouridis, I., Trivellas, P., \& Tsimonis, G. (2012). Using ES-QUAL to measure internet service quality of e-commerce web sites in Greece. International Journal of Quality and Service Sciences, 4(1), 86-98. https://dx.doi. org/10.1108/17566691211219751.

Schaupp, L. C. (2010). Web site success: Antecedents of web site satisfaction and reuse. Journal of Internet Commerce, 9(1), 42-64. https://dx.doi.org/10.1080/15332861.2010.487414.

Silva, M. A. L., \& Wijayaratne, I. D. A. L. (2015). Usability evaluation of University of 
Colombo library website: A case study. Annals of Library and Information Studies (ALIS), 62(1), 40-47.

Stokes, A., \& Jensen, T. D. (2011). Cobranding: The effects of e-tailer and delivery carrier familiarity on price and e-tailer perceptions. Journal of Marketing Theory and Practice, 19(1), 97-108.

Tamuliene, V., \& Murzaite, R. (2013). The influence of higher education image on students' loyalty in Lithuania. Transformation in Business \& Economics, 12(2), 196-214.

Vasauskaite, J., \& Streimikiene, D. (2014). Review of energy efficiency policies in Lithuania. Transformation in Business \& Economics, 13(3C), 628-642.

Vveinhardt, J., Andriukaitiene, R., \& Grancay, M. (2015). The preparation of companies in developing regions to become socially responsible: management culture assessment by employees. Transformation in Business \& Economics, 14(2B), 494-514.

Wachter, K. (2002). Longitudinal assessment of web retailers: issues from a consumer point of view. Journal of Fashion Marketing and Management: An International Journal, 6(2), 134-145. https://dx.doi. org/10.1108/13612020210429476.

Wang, J., \& Senecal, S. (2007). Measuring perceived website usability. Journal of Internet Commerce, 6(4), 97-112. https://dx.doi. org/10.1080/15332860802086318.
Antanas Ūsas

Lithuanian Sports University

Faculty of Sport Education

Department of Sport Management Economics and Sociology

Lithuania

AntanasUsas92@gmail.com

prof. Edmundas Jasinskas, Ph.D.

Lithuanian sports university

Faculty of Sport Education

Department of Sport Management Economics and Sociology

Lithuania

edmundas.jasinskas@Isu.It

prof. Dalia Štreimikienè, Ph.D.

Lithuanian Sports University

Faculty of Sport Education

Department of Sport Management Economics and Sociology

Lithuania

dalia.streimikiene@lsu.It

prof. Biruta Svagzdienè, Ph.D.

Lithuanian Sports University

Faculty of Sport Education

Department of Sport Management Economics and Sociology

Lithuania

biruta.svagzdiene@lsu.It

Artūras Simanavičius, Ph.D.

Lithuanian Sports University

Faculty of Sport Education

Department of Sport Management Economics

and Sociology

Lithuania

arturas.simanavicius@Isu.It 


\section{Abstract}

\section{QUALITY EVALUATION OF INTERNET WEBSITES WHICH REPRESENTS THE LITHUANIAN BASKETBALL THROUGH CONSUMERS APPROACH

\author{
Antanas Ūsas, Edmundas Jasinskas, Dalia Štreimikienè, Biruta Švagždienè,
} Artūras Simanavičius}

The information technology area is one of the fastest expanding and most customizable in daily activities. In 2015, 68\% Lithuanian households had personal computers and internet access at home.

The modern business is moving to virtual space. The exchange of business area develops a need to managerial decisions in a virtual space. All of the e-business areas have one main element - website. In Lithuanian basketball websites carried out aid communication, information dissemination, representation, sales features. Web site can serve as a key platform to help organizations deal with clients (Gonzalez et al., 2015). The Organization Web site becomes the face of organization and represent in cyberspace. Because of large number of websites and the competition, aspect of quality becomes increasingly important. Main questions are: in what consumers pay attention? How they understand the benefits of the website? What kind of emotional state caused by the Web site?

Analyzing techniques of websites evaluation three different groups were separated - quality, usability and satisfaction. The best technique - quality, which is the most universal and informative defining with other techniques. The quality of internet websites which represented the Lithuanian basketball satisfies the needs of consumers. The emotion which was experienced during the research was statistically insignificant influence but emotions experienced the last surfing minutes have statistically significant influence. Users, who had experienced positive emotions in the end of surfing, tend to evaluate better the internet website. It is important for organizations to manage their internet website that visitors leave it with positive emotions.

Key Words: Information and communications technologies, internet website, emotions.

JEL Classification: M15, M21, M31.

DOI: 10.15240/tul/001/2018-2-010 